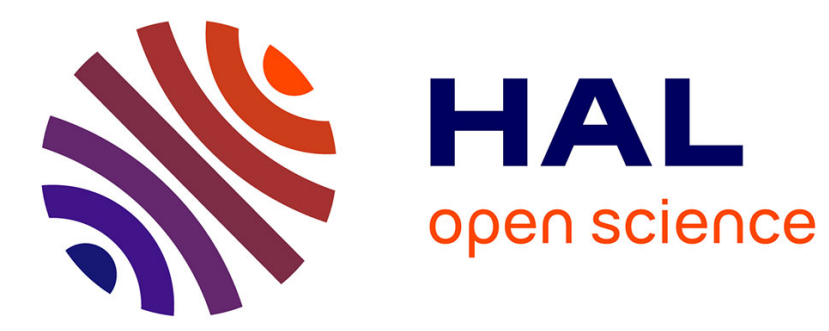

\title{
In vitro analysis of aggregation-disaggregation of the folding intermediate of Bacillus subtilis $\alpha$-amylase.
} Anne Colomer-Pallas, Marie-Françoise Petit-Glatron, Regis Chambert

\section{To cite this version:}

Anne Colomer-Pallas, Marie-Françoise Petit-Glatron, Regis Chambert. In vitro analysis of aggregation-disaggregation of the folding intermediate of Bacillus subtilis $\alpha$-amylase.. Journal of Biological Physics and Chemistry, 2002, 2, pp.101-107. hal-00019349

\section{HAL Id: hal-00019349 https://hal.science/hal-00019349}

Submitted on 21 Feb 2006

HAL is a multi-disciplinary open access archive for the deposit and dissemination of scientific research documents, whether they are published or not. The documents may come from teaching and research institutions in France or abroad, or from public or private research centers.
L'archive ouverte pluridisciplinaire HAL, est destinée au dépôt et à la diffusion de documents scientifiques de niveau recherche, publiés ou non, émanant des établissements d'enseignement et de recherche français ou étrangers, des laboratoires publics ou privés. 


\title{
In vitro analysis of aggregation-disaggregation of the folding intermediate of Bacillus subtilis $\alpha$-amylase
}

\author{
A. COLOMER-PALlAS, M.-F. PETIT-GLATRON and R. CHAMBERT*
}

Institut Jacques Monod, Laboratoire Génétique et Membranes, Centre National de la Recherche Scientifique, Universités Paris 6 et Paris 7, Paris, France

e-mail :colomer-pallas@ijm.jussieu.fr; glatron@ccr.jussieu.fr; chambert@ccr.jussieu.fr

*Author for correspondence.: Tour 43-2, place Jussieu

75251 Paris cedex 05, France. Tel: 331442747 19,

fax: 331442759 94, e-mail: chambert@ccr.jussieu.fr

Abbreviations:

TFE, 2,2,2 trifluoroethanol; Gdn-HCl, guanidium chloride; FTIR, Fourier transform infrared; ATR, attenuated total reflexion

Proteins and enzymes:

$\alpha$-amylase

AMY_BACSU

(EC 3.2.1.1)

\section{SUMMARY}

The refolding intermediate of Bacillus subtilis $\alpha$-amylase is prone to aggregate at $37^{\circ} \mathrm{C}$ and $\mathrm{pH} 7$ when the protein concentration is relatively high $(\geq 1 \mu \mathrm{M})$. Low concentrations of $2,2,2$ trifluoroethanol greatly increased the rate of aggregation. Aggregation made the folding intermediate resistant to proteases and there was kinetic competition between aggregation and proteolytic degradation. Analysis by Fourier transform infrared spectroscopy indicated that the secondary structure of the refolding intermediate is sightly different under soluble or aggregated states. Aggregates were readily solubilized by guanidium chloride $\left(D_{1 / 2}=1.25 \mathrm{M}\right)$, but disaggregation was slow when aggregates were resuspended in solutions of various foreign native proteins under physiological conditions of $\mathrm{pH}$ and temperature. This destabilizing effect resulting from protein-protein interactions may make the aggregation process reversible in vivo.

Keywords:

Alpha-amylase, Bacillus subtilis protein secretion, aggregation-disaggregation, folding intermediate

\section{INTRODUCTION}

Previous studies [1] of the refolding pathway of $B$. subtilis $\alpha$-amylase showed that the unfoldingrefolding transition of this protein proceeds via two steps with a partially folded intermediate. Even though refolding experiments were carried out at a dilute protein concentration $(<10 \mu \mathrm{g} / \mathrm{ml})$, a decrease in the yield of refolding was observed when the intermediate was transiently accumulated by blocking the process during which it folds into the native conformation. It was suspected that the intermediate slowly aggregated under such conditions.

Since in vitro refolding experiments were carried out under physiological conditions of $\mathrm{pH}$, ionic strength and temperature, we postulated that studies of the aggregate's properties such as the dynamics of formation, the structure of the protein subunit that forms the aggregate, and its stability, might provide information about this side effect of refolding which occurs in vivo mainly when the protein is overproduced [2].

Aggregation of partially folded proteins is currently considered to be an irreversible process that is driven by interaction between the solvent and exposed hydrophobic surfaces that are normally buried within the native structure. It has been shown that the protein concentration or the presence of amphipathic compounds that facilitate the exposure of hydrophobic surfaces are factors that increase the yield and the rate of this aggregation process. The stability of aggregates probably depends, however, on both the state of folding of the protein molecules that aggregate and the physico chemical properties of the medium in which aggregates are dispersed. Disaggregation can occur spontaneously without any aid as was demonstrated from studies of the maltose binding protein folding at micromolar protein concentrations [3]. In the case of isolated 
inclusion bodies, disaggregation can be achieved only in the presence of a strong denaturant such as Gdn- $\mathrm{HCl}[4]$.

Allowing for this, we undertook in this work the in vitro characterization of the aggregationdisaggregation transition of the $\alpha$-amylase folding intermediate under conditions partially mimicking the in vivo environment.

The fact that $\alpha$-amylase is an exocellular protein strongly suggests that in vivo the unfolded nascent polypeptide chains are transiently in contact with amphipathic compounds such as membrane phospholipids. We therefore used low concentrations of TFE to mimick such a local cellular environment [5].

\section{MATERIALS AND METHODS}

Purification of exocellular $\alpha$-amylase $\alpha$-amylase was prepared from the culture supernatant of B. subtilis GM96101 (degU32 (Hy), sacA321, $\Delta$ sacRsacB, sacRamyE), a derivative of $B$. subtilis 168 [6]. A stock solution of pure protein (60 $\mathrm{mg} / \mathrm{ml}$ ) was prepared in $0.1 \mathrm{M}$ potassium phosphate, at $\mathrm{pH} 7$.

Assay of $\alpha$-amylase

$\alpha$-amylase activity was assayed at $37^{\circ} \mathrm{C}$, using $\mathrm{p}$ nitrophenylmaltotrioside as a substrate (bioMerieux) at $\mathrm{pH} 6.3$ in $0.1 \mathrm{M}$ potassium phosphate. One enzyme unit corresponds to $25 \mu \mathrm{g}$ pure $\alpha$ amylase.

Fluorescence measurements

Changes in intrinsic fluorescence and the fluorescence spectra of $\alpha$-amylase were recorded with a F2000 Hitachi thermoregulated spectrofluorimeter.

FTIR spectroscopy

We used a Bruker vector 22 equipped with an MCT detector. Spectra were obtained from 100 summed interferograms at a resolution of $4 \mathrm{~cm}^{-1}$ for each measurement. Fourier self deconvolution was performed with FD software (Spectrum Square Associates) implemented with GRAMS (Galactic Ind Co) [7]. Fourier derivation was performed using RAMOP software [8]. We estimated the amount of the various secondary structures from the FTIR data by fitting Gaussian peaks at each frequency (see text) to the deconvoluted spectrum and calculating their area relative to the amide I band using GRAMS software.

\section{RESULTS}

3.1 Competition between folding and aggregation when unfolded $\alpha$-amylase is at a high concentration and in the presence or absence of TFE
The unfolding-refolding transition of $\alpha$ amylase at $37^{\circ} \mathrm{C}$ and $\mathrm{pH} 7$ proceeds via two-steps [1] with a partially folded intermediate. This intermediate can be stabilized in a calcium-free refolding medium. This metal ion triggers the conversion to the protein to its native state, and the transition can be monitored by changes in protein intrinsic fluorescence. Previous studies on the unfolding-folding transition used low concentrations of protein $(\approx 0.1 \mu \mathrm{M})$. We reinvestigated the transition with high concentrations of protein $(\approx 1 \mu \mathrm{M})$ and in the presence of low concentrations of TFE. Gradually adding TFE to the refolding medium led to a decrease in the refolding yield (Fig. 1). The $\alpha$ amylase folding intermediate refolded rapidly, $\mathrm{t}_{1 / 2}=$ $78 \pm 2 \mathrm{~s}$, with a yield of $61 \%$ in the absence of TFE (Fig. 1A). Refolding was totally inhibited in $10 \%$ TFE due to the formation of aggregates, as demonstrated by the distribution of $\alpha$-amylase between the soluble phase and the protein pellet after centrifugation of the refolding medium (Fig. 1B). There was partial aggregation of the refolding intermediate, even in the absence of TFE. The soluble refolded $\alpha$-amylase in the supernatant had the same specific enzyme activity as the native protein, while resuspended aggregates were devoid of any enzyme activity. Native $\alpha$-amylase remained in a soluble and active form when incubated under the same conditions of $\mathrm{pH}$ and temperature within the same range of TFE concentrations (not shown). These results therefore indicate that the refolding intermediate tends to aggregate rather than fold when it is at a high concentration and in the presence of an amphipathic compound. Since it was shown from various model proteins that no substantial structural changes occur at these low TFE concentrations $[9,10]$, it can be postulated that the net effect of this solvent must be to strengthen the interactions between the individual monomeric units involved in aggregates.

\subsection{Kinetics of aggregation of $\alpha$-amylase refolding intermediate}

The formation of aggregates from the stabilized folding intermediate I, incubated at $37^{\circ} \mathrm{C}$, was detected by an increase in light scattering at $340 \mathrm{~nm}$ (Fig. 2). We assumed a constant mean aggregation number, $n$, for aggregates and postulated that the rate of aggregation is controlled by an initial step that has a reaction order $\alpha$. The differential rate of the aggregation reaction is thus:

$$
\frac{\mathrm{d}(\mathrm{nI})}{\mathrm{dt}}=\mathrm{k}(\mathrm{a}-\mathrm{nI})^{\alpha}
$$

where $\mathrm{k}$ is the apparent rate constant of aggregation and $a$ the initial concentration of the 
folding intermediate. The integrated form of this equation is

$$
\mathrm{kt}=\frac{1}{\alpha-1}\left[\frac{1}{(\alpha-\mathrm{nI})^{\alpha-1}}-\frac{1}{\mathrm{a}^{\alpha-1}}\right]
$$

and

$$
\mathrm{t}_{1 / 2}=\frac{2^{\alpha-1}-1}{(\alpha-1) \mathrm{ka}^{\alpha-1}}
$$

The value of $(\mathrm{a}-\mathrm{nI})$, which is the concentration of the folding intermediate that remains unaggregated at any time during aggregation, is proportionel to the difference in absorbance $\Delta \mathrm{A}_{\mathrm{t}}=\mathrm{A}_{\infty}-\mathrm{A}_{\mathrm{t}}$.

The kinetic parameters $\alpha$ and $t_{1 / 2}$ were evaluated (Table 1) by fitting the curves in Fig. 2. The value of the reaction order $(\alpha)$ of the aggregation reaction is close to 2 , implying that the rate of aggregation is controlled by an initial dimerization step.

The kinetics of the aggregation in $15 \%$ TFE was monitored with respect to the initial concentration of the folding intermediate. As expected for the reaction with a reaction order $>1$, the half-time of the process decreased with an increase in the initial concentration of the unfolded protein (Fig. 3A). The kinetic parameters of aggregation were evaluated from a plot of $\ln t_{1 / 2}$ versus (ln $a)$ (Fig. 3B). The parameters obtained were: $\alpha=1.80 \pm 0.05$ and

$$
\mathrm{k}=0.46 \pm 0.02 \mu \mathrm{M}^{-1} \mathrm{~min}^{-1} \text {. }
$$

\subsection{Physico-chemical properties of the aggregates of $\alpha$-amylase refolding intermediate}

FTIR spectroscopy

Estimates of the secondary structure content of the native $\alpha$-amylase and of the stabilized refolding intermediate indicated that the latter was partially folded [1]. We therefore investigated whether the secondary structure content was preserved or modified in the aggregated state.

The FTIR spectroscopy results indicated that the native $\alpha$-amylase and the aggregated form of its folding intermediate had somewhat different secondary structures (Fig. 4, Table 2). Most of the information on the protein's secondary structure is contained in the amide I band [7]. Resolutionenhancement procedures such as Fourier selfdeconvolution and Fourier-derivation were used to resolve the components (Fig. 4B) underlying the broad amide I band contour because of marked overlap in the spectra (Fig. 4A). The components revealed by the two methods were similar. There were three main components at 1687, 1652 and $1633 \mathrm{~cm}^{-1}$ for the native protein and three main components at 1685,1641 and $1618 \mathrm{~cm}^{-1}$ for the aggregates of the refolding intermediate.

The native protein mainly had components assigned to $\beta$-sheets (with a low frequency component at $1633 \mathrm{~cm}^{-1}$ and a high frequency component at $\left.1687 \mathrm{~cm}^{-1}\right)$ and to $\alpha$-helices $\left(1652 \mathrm{~cm}^{-}\right.$ ${ }^{1}$ ). Fitting the component bands to the amide I contour gave an estimate of the relative amount of secondary structure (Table 2).

The aggregates of the refolding intermediate had a strong component at $1618 \mathrm{~cm}^{-1}$. This low frequency component, associated with the high frequency found at $1685 \mathrm{~cm}^{-1}$, is assigned to aggregated structures such as intermolecular $\beta$ strands [11]. The band at $1641 \mathrm{~cm}^{-1}$ is broad, suggesting that it is made up of smaller overlapping, unresolved bands induced not only by $\beta$-sheets $\left(1648 \mathrm{~cm}^{-1}\right)$, but also by disordered structures and possibly $\alpha$-helices $\left(1656 \mathrm{~cm}^{-1}\right) \quad($ Table 2$)$. Comparison with the secondary structure content of the soluble refolding intermediate evaluated previously from far U.V. CD spectroscopy [1] indicated that aggregation led mainly to an increase in the amount of $\beta$-sheet.

\section{Resistance to proteolysis}

We have demonstrated that the refolding intermediates of $\alpha$-amylase [1] are sensitive to proteases, in contrast to the native form, but there is no evidence of this when the refolding intermediate is an aggregate. We examined the possibility of kinetic competition between aggregation and proteolytic degradation, postulating that such competition could be important in vivo, since there are many proteases associated with the $B$. subtilis envelope.

The first part of this work shows that the rate of aggregation of the refolding intermediate is greatly increased by TFE. We went on to examine this competition over a range of TFE concentrations. The results indicated that the refolding intermediate does not undergo proteolytic degradation when it is very rapidly aggregated (Fig. $5)$.

\subsection{Effectors of disaggregation}

The strong denaturing agent $\mathrm{Gdn}-\mathrm{HCl}$ has been used to solubilize inclusion bodies resulting, in vivo, from the irreversible aggregation of unfolded overexpressed proteins. We established the curve describing the solubilization of $\alpha$-amylase from aggregates by $\mathrm{Gdn}-\mathrm{HCl}$, at $\mathrm{pH} 7$ and $37^{\circ} \mathrm{C}$, by measuring the protein in the soluble and insoluble phases after incubating the aggregates in various concentrations of denaturant. Concentrations of $\mathrm{Gdn}-\mathrm{HCl}$ above one molar caused abrupt disaggregation (Fig. 6). This could reflect the cooperative nature of the interactions stabilizing the 
aggregated state. $D_{1 / 2}$, the mid-point of the solubilization curves was approximately $1.25 \mathrm{M}$. This indicates that the intermolecular interactions are weaker in these aggregates than in inclusion bodies, which are solubilized by higher $\mathrm{Gdn}-\mathrm{HCl}$ concentrations. Therefore, in order to test the possible reversibility of aggregation of the $\alpha$ amylase folding intermediate under cytosolic conditions, we studied the stability of aggregates resuspended in a solution of foreign proteins under physiological conditions of $\mathrm{pH}$, ionic strength and temperature. We postulated that protein-protein interactions could destabilize the aggregates. The results obtained (Fig. 7) confirmed this hypothesis and showed that bovine serum albumin, a protein known to bind a variety of hydrophobic compounds [12], was the more efficient effector of disaggregation.

\section{DISCUSSION}

We have shown here that the $\alpha$-amylase folding intermediate is prone to form insoluble aggregates. The ratio of aggregation may be controlled by an initial dimerization step, since the order of the reaction is close to 2 .

The $\alpha$-amylase monomers that make up the aggregates were slightly different in their secondary structures from their soluble counterparts. The aggregation process, however, caused the protein to become resistant to protease. One of the most striking features of the aggregates is their instability under conditions that mimic the cytosolic environment. Protein-protein interactions under mild conditions of $\mathrm{pH}$, ionic-strength and temperature promote disaggregation. One can thus ask the question whether aggregation of partially folded protein is always an irreversible process in vivo. It is currently accepted that under such an environment, the chaperonin system prevents aggregation [13] by shielding the hydrophobic surfaces of unfolded proteins. GroEL and GroES, the two components of the chaperone machinery, are present in the B. subtilis cytosol [14]. However, the fact that the cellular interior is very crowded with proteins suggests that there are strong proteinprotein interactions which might affect the reaction rates and equilibria of many macromolecular reactions [15].

\section{ACKNOWLEDGEMENTS}

We thank Alain Desbois and Bruno Robert (Commissariat à l'Energie Atomique, Saclay, France) for assistance in acquiring FTIR spectra, and Agnès Troullier (Institut Jacques Monod) for analysis of FTIR data. We thank Antonia Kropfinger for revising the English text. This work was supported by a grant from the European Union (Biotech programme QLK3-CT-1999-00413).

\section{REFERENCES}

1. Haddaoui, E.A., Leloup, L., Petit-Glatron, M.F. \& Chambert, R. Characterization of a stable intermediate trapped during reversible refolding of Bacillus subtilis -amylase. Eur. J. Biochem. 249 (1997) 505-509.

2. Speed, M.A., Wang, D.I.C. \& King, J. Specific aggregation of partially folded polypeptide chains: the molecular basis of inclusion body composition. Nature Biotechnology 14 (1996) 1283-1287.

3. Ganesh, C., Zaidi, F.N., Udgaonkar, J.B. \&Varadarajan, R. Reversible formation of onpathway macroscopic aggregates during the folding of maltose binding protein. Protein Sci. 10 (2001) 1635-1644.

4. Middelberg, A. Preparative protein refolding. Trends Biotechnol. 20 (2002) 437-'43.

5. Jones, J.D., McKnight, C.J. \& Gierasch, L.M. Biophysical studies of signal peptides: implications for signal sequence functions and the involvement of lipid in protein export. J. Bioenerg. Biomemb. 22 (1990) 213-232.

6. Leloup, L., Haddaoui, E., Chambert, R. \& PetitGlatron, M.F. Characterization of the rate limiting step of the secretion of Bacillus subtilis -amylase overproduced during the exponential phase of growth. Microbiology 143 (1997) 3295-3303.

7. Goormaghtigh, E., Cabiaux,V. \& Ruysschaert J.M. Determination of soluble and membrane protein structure by Fourier transform infrared spectroscopy. Subcell. Biochem. 23 (1994) 405-450.

8. Cameron, D.G. \& Moffatt, D.J. A generalized approach to derivative spectroscopy. Applied spectroscopy 41 (1987) 539-544.

9. Buck, M., Radford, S.E. \& Dobson, C.M. A partially folded state of hen egg white lysozyme in trifluoroethanol: structural characterization and implications for protein folding. Biochemistry 32 (1993) 669-678.

10. Slupsky, C.M., Kay, C.M., Reinach, F.C., Smillie, L.B. \& Sykes, B.D. Calcium-induced dimerization of troponin C: mode of interaction and use of trifluoroethanol as a denaturant of quaternary structure. Biochemistry 34 (1995) 7365-7375.

11. Allison, S.D., Dong, A. \& Carpenter, J.F. Counteracting effects of thiocyanate and sucrose on chymotrypsinogen secondary structure and aggregation during freezing, drying, and rehydration. Biophys. J. 71 (1996) 2022-2032.

12. Demant, E.J., Richeri, G.V., Kleinfeld, A.M. Stopped-flow kinetic analysis of long-chain fatty 
acid dissociation from bovine serum albumin Biochem. J. 36 (2002) 809-815.

13. Ellis, R.J. \& Hartl, F.U. Protein folding in the cell: competing models of chaperonin function. FASEB J. 10 (1996) 20-26.

14. Tozawa, Y., Yoshikawa, H., Kawamura, Itaya, M. \& Takahashi, H. Isolation and characterization of the groES and groEL genes of Bacillus subtilis Marburg. Biosci. Biotechnol. Biochem. 56 (1992) 1995-2002.

15. Ellis, R.J. Macromolecular crowding: obvious but underappreciated. Trends Biochem. Sci. 26 (2001) 597-604. 
Table 1. Reaction orders and half-times of the aggregation of the $\alpha$-amylase refolding intermediate.

Kinetic data were analyzed by non linear least squares fitting to the integrated rate equation given in the text (the Sigma Plot curve fitting programme).

\begin{tabular}{rll}
\hline $\begin{array}{l}\% \text { TFE } \\
\text { order }(\alpha)\end{array}$ & reaction & half-time (s) \\
\hline & & \\
0 & $1.81 \pm 0.04$ & $960 \pm 35$ \\
10 & $1.82 \pm 0.05$ & $274 \pm 15$ \\
15 & $1.89 \pm 0.09$ & $145 \pm 6$ \\
\hline
\end{tabular}

Table 2. Secondary structure of $\alpha$-amylase in native state and aggregated state.

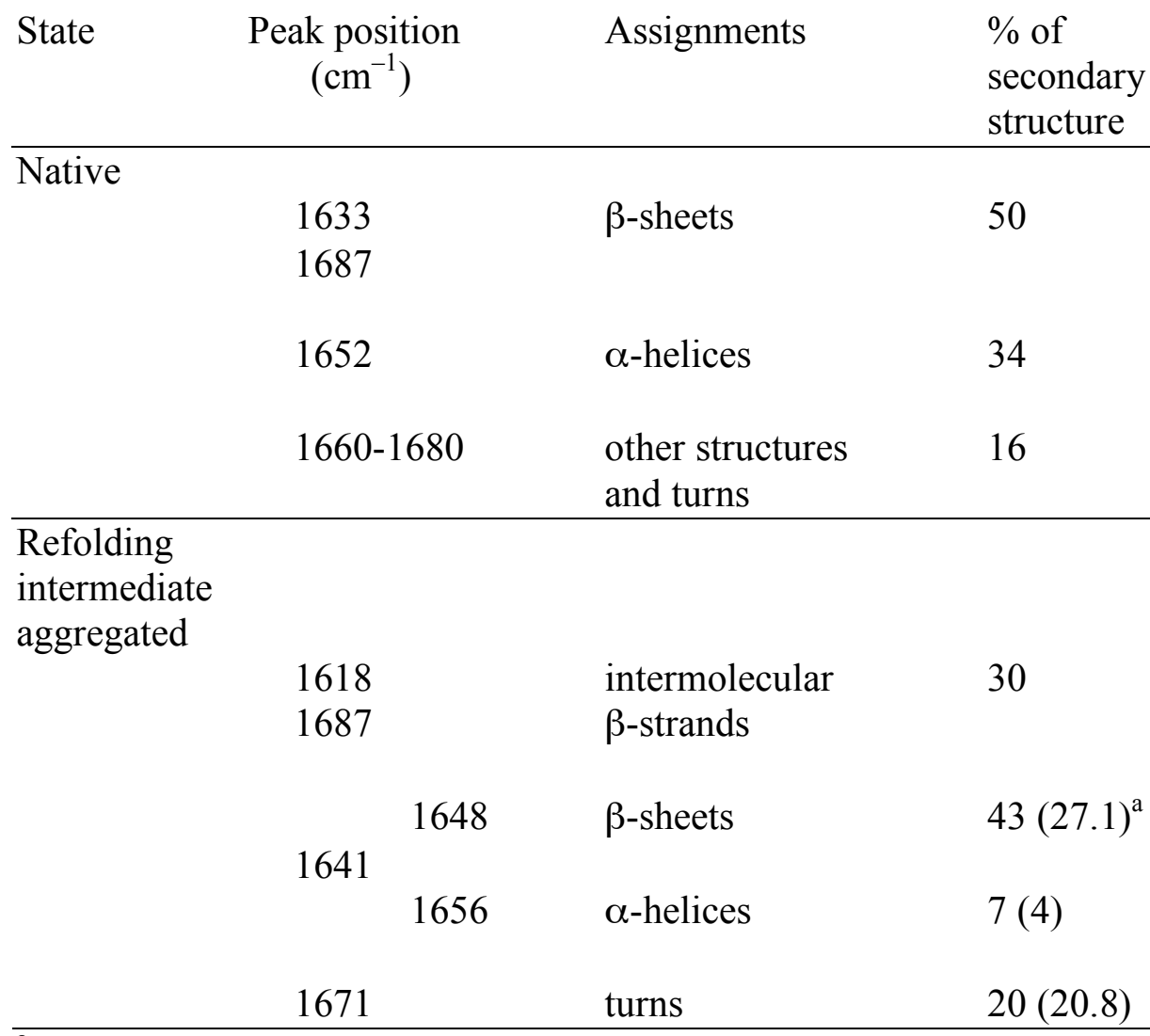

${ }^{a}$ Numbers in parenthesis refer to the secondary structure of the refolding non-aggregated form of the intermedite of $\alpha$-amylase evaluaated via U.V. CD stpectroscopy [1]. 

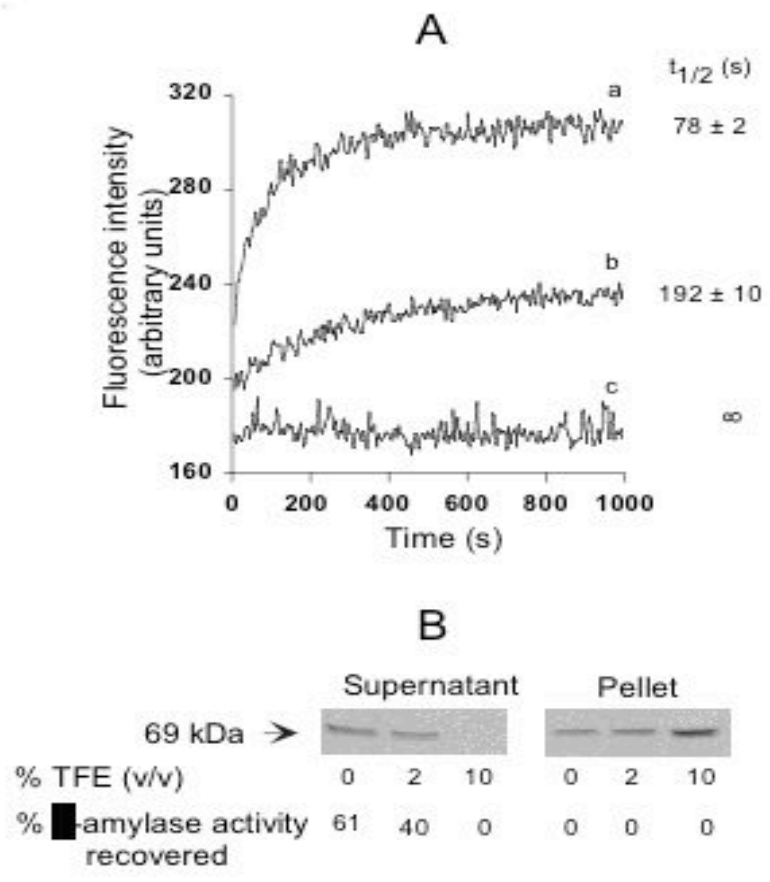

Fig. 1. Competition between folding and aggregation of the $\alpha$-amylase refolding intermediate in the presence of increasing concentrations of TFE.

The refolding intermediate was obtained by a two-step procedure : $\alpha$-amylase was first totally unfolded by mixing $1 \mu 1$ of $\alpha$-amylase stock solution $(60 \mathrm{mg} / \mathrm{ml})$ with $5 \mu 16 \mathrm{M} \mathrm{Gdn}-\mathrm{HCl}$. After $10 \mathrm{~min}$ incubation at $37^{\circ} \mathrm{C}$, the denaturing mixture was then diluted with $0.5 \mathrm{ml} 0.1 \mathrm{M}$ sodium phosphate at $\mathrm{pH} 7$ containing $0.1 \mathrm{mM}$ EDTA. The refolding intermediate formed almost instantaneously in such conditions [1]. Folding of the intermediate was initiated by adding $0.5 \mathrm{ml}$ phosphate buffer containing $1 \mathrm{mM} \mathrm{CaCl}_{2}$ and $4 \%$ or $20 \% \mathrm{TFE}$ at $37^{\circ} \mathrm{C}$.

A) Changes in fluorescence intensity were recorded at $344 \mathrm{~nm}$, the excitation wavelength was $280 \mathrm{~nm}$. The dead time for mixing was approximately $8 \mathrm{~s}$. The final concentration of TFE in the refolding reaction mixture were 2 $\%$ (b), and $10 \%$ (c). (a) was a control without TFE. The half time of refolding $\left(\mathrm{t}_{1 / 2}\right)$ for each condition is indicated on the right of the refolding curves.

B) Partitioning between the soluble native state and the aggregated state was measured by enzymatic assay and SDS-PAGE analysis. After recording the fluorescence intensity, the samples were centrifuged (12000 g, $15 \mathrm{~min})$ and the protein pellets resuspended in $1 \mathrm{ml} 0.1 \mathrm{M}$ sodium phosphate at $\mathrm{pH} 7$ containing $0.5 \mathrm{mM} \mathrm{CaCl} 2$. Enzyme activity was measured with $25 \mu \mathrm{l}$ supernatant and $25 \mu \mathrm{l}$ resuspended aggregates from each sample, and SDSPAGE was performed using $60 \mu 1$ aliquots. 
Figure 2

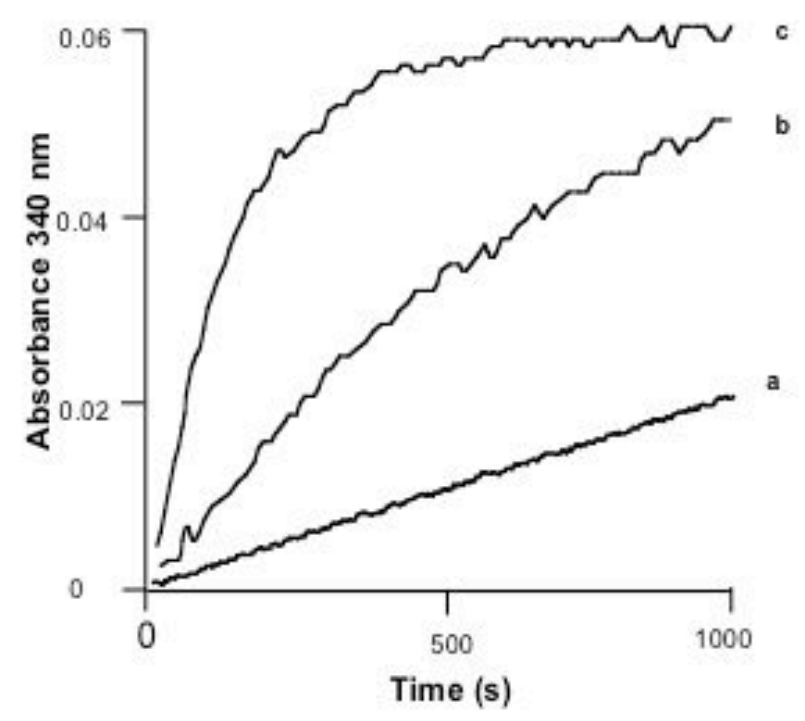

Fig. 2. Kinetics of the aggregation of $\alpha$-amylase refolding intermediate monitored by the increase in light scattering at $340 \mathrm{~nm}$.

The refolding intermediate was prepared as described in the legend to Fig. 1. Aggregation was initiated by mixing $0.5 \mathrm{ml}$ refolding intermediate solution with $0.5 \mathrm{ml}$ of $0.1 \mathrm{M}$ potassium phosphate at $\mathrm{pH} 7$, containing 0.1 mM EDTA and TFE. The final concentration of TFE in the refolding reaction mixture was $15 \%$ (c) or $10 \%$ (b). (a) was the control without TFE. The final concentration of protein in the aggregation mixtures was $60 \mu \mathrm{g} / \mathrm{ml}$. Changes in light scattering at $340 \mathrm{~nm}$ were monitored using a Unicam spectrometer thermoregulated at $37^{\circ} \mathrm{C}$. The dead time was $8 \mathrm{~s}$. 
Figure 3
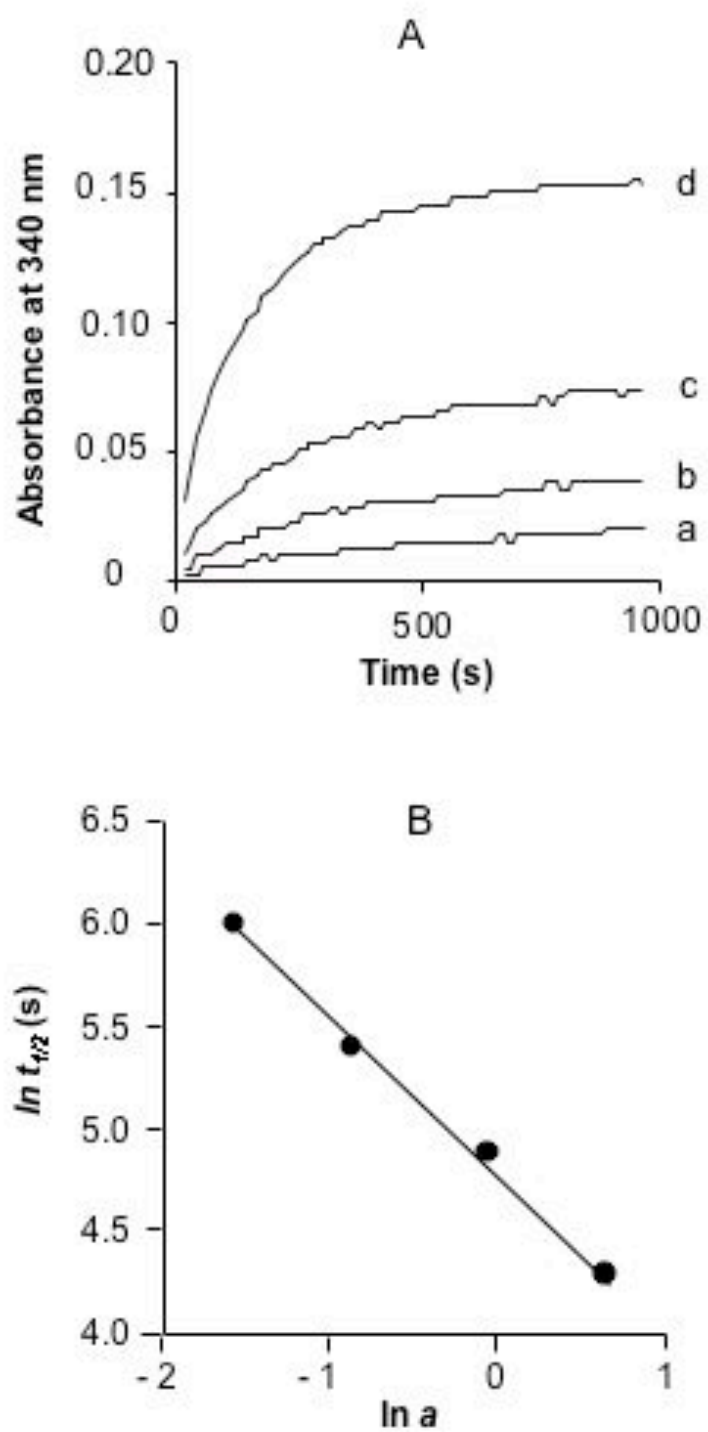

Fig. 3. Kinetics of aggregation of the refolding intermediates of $\alpha$-amylase in $15 \%$ TFE at various initial protein concentrations.

A) The refolding intermediate was prepared as described in the legend to Fig. 1. The amounts of protein subjected to unfolding were calculated so that the final concentrations of the refolding intermediate in the aggregation mixture were $15 \mu \mathrm{g} / \mathrm{ml}$ (a), $30 \mu \mathrm{g} / \mathrm{ml}$ (b), $60 \mu \mathrm{g} / \mathrm{ml}$ (c) and $120 \mu \mathrm{g} / \mathrm{ml}$ (d).

B) Plot of $\ln a$ against $\ln t_{1 / 2}$. 
Figure 4
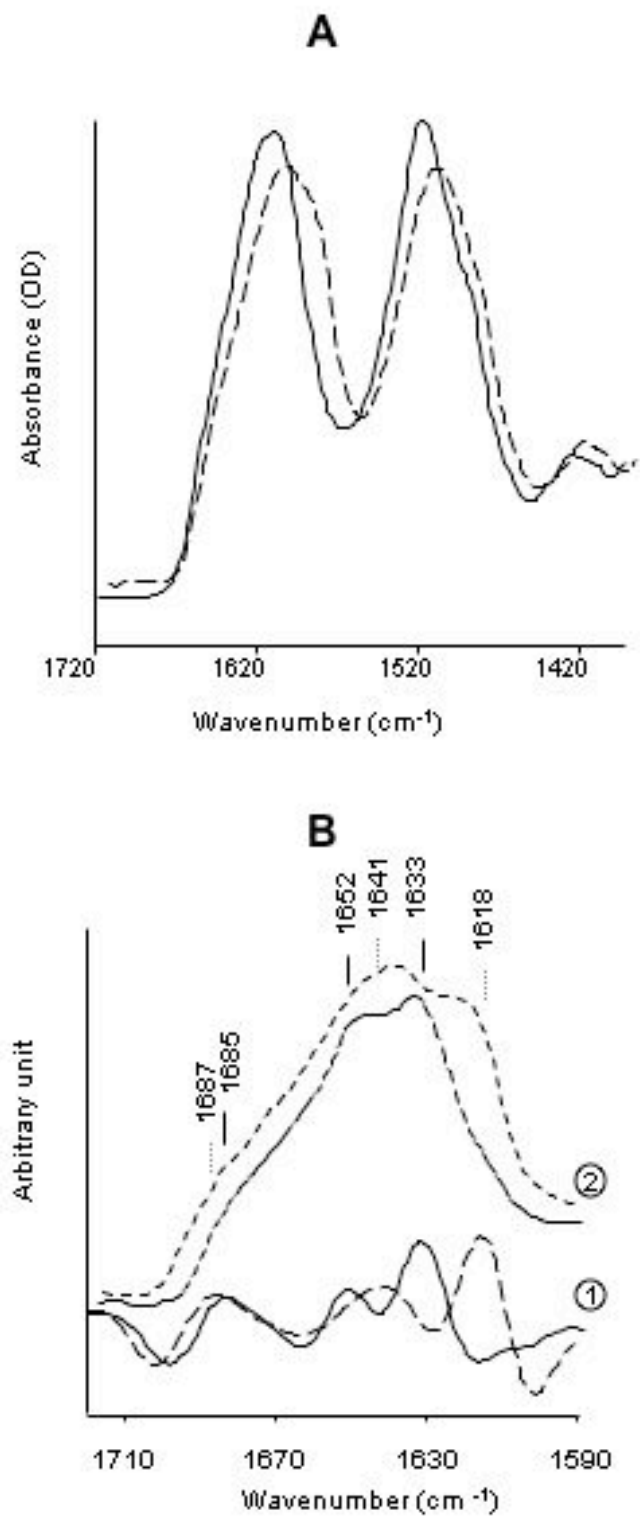

Fig. 4. ATR IR spectra of $\alpha$-amylase in the native state (black line) and folding intermediate aggregates (dotted line).

The refolding intermediate was prepared as described in the legend to Fig. 1. Aggregation was carried out as described in the legend to Fig. 3. The final concentration of the refolding intermediate in the aggregation mixture was $60 \mu \mathrm{g} / \mathrm{ml}$. Aggregates were centrifuged for $20 \mathrm{~min}$ at $12000 \mathrm{~g}$ and washed with buffer only. The pellet corresponding to $60 \mu \mathrm{g}$ protein was resuspended in $2 \mu 10.1 \mathrm{M}$ potassium phosphate at $\mathrm{pH} 7$. For the control, $1 \mu 1$ $\alpha$-amylase stock solution $(60 \mathrm{mg} / \mathrm{ml}$ ) was mixed with $1 \mu \mathrm{l} 0.1 \mathrm{M}$ potassium phosphate at $\mathrm{pH}$ 7. Samples were deposited on the ATR crystal.

A) Normalized absorbance spectra

B) Second derivative amide I (1) and self deconvolution (2) spectra derived fromA. 
Figure 5

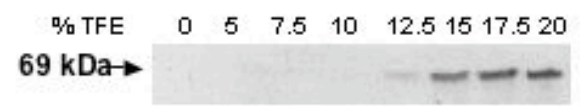

Fig. 5. Kinetic competition between aggregation and proteolysis of the refolding intermediate of $\alpha$ amylase.

$\alpha$-amylase ( $2 \mu 1$ stock solution) was mixed with $12 \mu 16 \mathrm{M} \mathrm{Gdn}-\mathrm{HCl}$. After $10 \mathrm{~min}$ at $37^{\circ} \mathrm{C}$, the refolding intermediate was stabilized by diluting the denaturing mixture in $1 \mathrm{ml} 0.1 \mathrm{M}$ sodium phosphate at $\mathrm{pH} 7$ containing $1 \mathrm{mM}$ EDTA at $37^{\circ} \mathrm{C}$. A set of Eppendorf tubes containing subtilisin and TFE was prepared. Drops of each solution were added separately in the bottoms of the tubes. The final concentration of subtilisin was increased as the TFE concentration increased to counterbalance inhibition of subtilisin by TFE. Aliquots of refoldidng intermediate solution $(100 \mu \mathrm{l})$ were rapidly introduced into each tube, and quickly mixed with the TFE and subtilisin. After 5 min incubation, $0.1 \mathrm{M}$ PMSF $(5 \mu \mathrm{l})$ was added and the samples were analysed by SDS PAGE. 
Figure 6

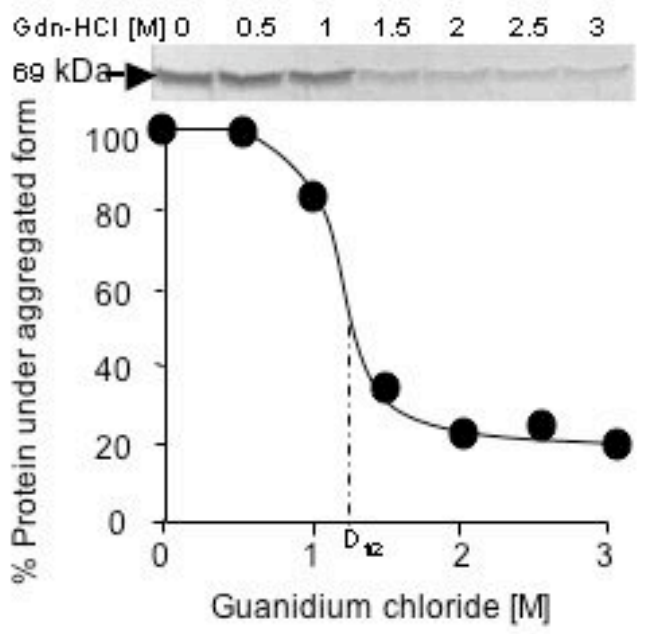

Fig. 6. Solubilization of $\alpha$-amylase aggregates by Gdn-HCl.

The totally unfolded protein, obtained from incubating $2 \mu \mathrm{l}$ stock solution with $8 \mu \mathrm{l} 6 \mathrm{M} \mathrm{Gdn}-\mathrm{HCl}$, was diluted in $1.7 \mathrm{ml} 0.1 \mathrm{M}$ sodium phosphate at $\mathrm{pH} 7$ containing $0.5 \mathrm{mM}$ EDTA. Aggregates were formed by additing $0.3 \mathrm{ml}$ TFE. The suspensions of aggregates were divided into 10 fractions of $0.2 \mathrm{ml}$ each and centrifuged $(20 \mathrm{~min}, 12000$ g). The supernatants were discarded and the pellets (approximately $12 \mu \mathrm{g}$ protein) were resuspended in $0.1 \mathrm{ml}$ $0.1 \mathrm{M}$ sodium phosphate buffer at $\mathrm{pH} 7$ containing $0.5 \mathrm{mM}$ EDTA and increasing concentrations of $\mathrm{Gdn}-\mathrm{HCl}$ and then incubated at $37^{\circ} \mathrm{C}$ for two hours. The samples were centrifuged and the supernatants and pellets were analysed by SDS PAGE. A-amylase in the soluble phase and pellet was quantified by densitometry of Coomassie blue stained gels using the NIH Image program. Prolonged incubation in Gdn-HCl did not significantly modify the result. 


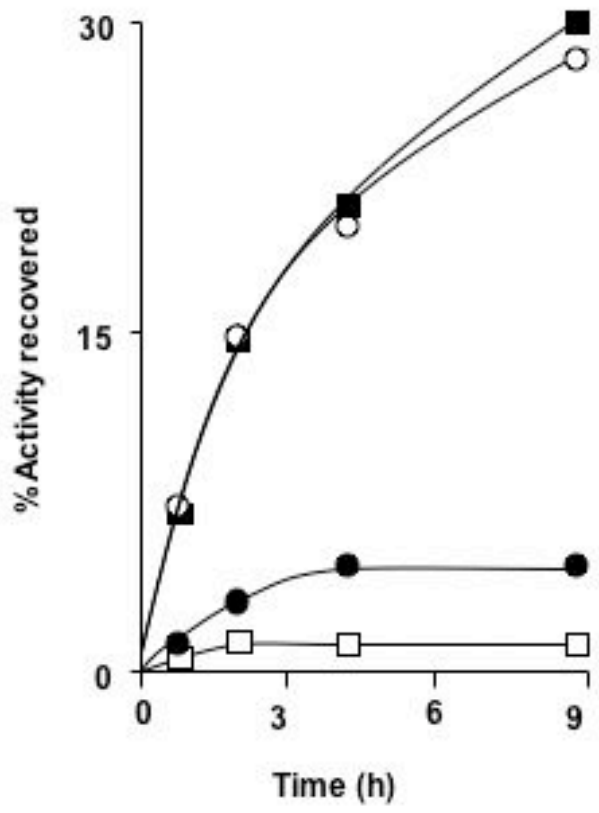

Fig. 7. Effect of foreign proteins on the stability of $\alpha$-amylase aggregates.

Aggregates of $\alpha$-amylase refolding intermediates were prepared as described in the legend to Fig.4. The aggregates were resuspended in $0.1 \mathrm{M}$ sodium phosphate buffer at $\mathrm{pH} 7$ containing $0.5 \mathrm{mM} \mathrm{Ca}^{2+}$ and $1 \mathrm{mg} / \mathrm{ml}$ of BSA ( $\bullet)$, ovalbumin $(\bigcirc)$ or lysozyme $(\bullet)$. Control without protein $(\square)$.

The suspensions were incubated at $37^{\circ} \mathrm{C}$ and $50 \mu 1$ samples were withdrawn and centrifuged at intervals. The supernatants were mixed with $0.25 \mathrm{ml} 0.1 \mathrm{M}$ sodium phosphate buffer at $\mathrm{pH} 7$ containing $0.5 \mathrm{mM} \mathrm{Ca}^{2+}$ for 15 $\mathrm{min}$, and the enzyme activity was assayed. The recovery of active soluble enzyme activity was evaluated with respect to the amount of unfolded enzyme used to prepare the aggregates. 